\title{
O diálogo entre o antigo e o moderno: Análise Digital do novo prédio para o Colégio Técnico de Campinas - Cotuca
}

\author{
Tais Caroline Pavani (IC), Prof. Dra. Eloisa Dezen-Kempter (PQ)
}

\begin{abstract}
Resumo
Este projeto de iniciação científica teve como objetivo produzir a modelagem do novo prédio projetado para o Colégio Técnico de Campinas (COTUCA) empregando novas tecnologias da informação e comunicação, como a modelagem da informação da construção (BIM - Building Information Modeling). O modelo resultante teria um caráter histórico-documental, ao retratar todas as áreas que compõem o conjunto de edifícios do COTUCA, abrangendo desde sua situação passada até os dias atuais. As atividades concentraram-se em revisão bibliográfica sobre a ferramenta BIM e sua aplicação em pré-existências; treinamento em software BIM, visando o empregado desta tecnologia no levantamento do edifício. Os documentos de tombamento do edifício, tanto municipal (CONDEPAAC) quanto estadual (CONDEPHAAT), foram consultados para elaborar o levantamento cronológico do caso de estudo. Finalmente procedeu-se ao levantamento fotográfico detalhado do conjunto arquitetônico que serviu de referência para outra pesquisa desenvolvida no mesmo local.
\end{abstract}

\section{Palavras Chave: BIM, PATRIMÔNIO HISTÓRICO, CONSERVAÇÃO}

\section{Introdução}

O modelo BIM constitui uma descrição digital tridimensional de uma construção. Essa tecnologia está sendo adotada na área de arquitetura, engenharia e construção no Brasil e encontra-se largamente difundida no âmbito internacional. É uma ferramenta eficiente para realizar simulações, armazenar informações de todos os componentes do edifício, assim como listar materiais e custos relativos e absolutos da obra com dados do modelo.

O uso de novas tecnologias digitais (BIM) contribuirá para tomadas de decisões dos projetos de intervenção, restauração e reabilitação.

O modelo 3D BIM, de acordo com o NIBS (2007), pode ser resumido como uma:

"Representação virtual das características físicas e funcionais de uma edificação, por todo o seu ciclo de vida, servindo como um repositório compartilhado de informações para colaboração" (NIBS, 2007 apud Sinduscon, s.d.).

\section{Resultados e Discussão}

As vantagens da utilização do sistema de modelagem BIM na área de Patrimônio Histórico ainda estão sendo exploradas, mas os benefícios diretos advindos do uso desta tecnologia em novas construções poderão ser estendidos para préexistências, principalmente aqueles relacionados com facilities managment.

Assim o uso desta tecnologia no caso de estudo selecionado, mostrou grande potencialidade, como criar um banco de dados do projeto que possibilite o entendimento integral da edificação histórica, visualização de elementos específicos que visa diminuir conflitos e imprecisões nas etapas de conservação e restauro, visualização dinâmica do edifício para fins de projetos de reuso, entre outros.

\section{Conclusões}

A troca de informação entre sistemas, é essencial para o ótimo desempenho do BIM já que depende da troca de informações sobre o modelo de edifício e suas fases.

O uso do modelo 3D permite que a compreensão do projeto seja acessível a todos e não só para o profissional que conhece todo o sistema.

Por fim podemos entender que Building Information Modeling é uma forma de projetar, construir e gerenciar. Sendo aplicado em todo o ciclo de vida do projeto, ajudando no impacto ambiental e até mesmo no custo da construção.

\section{Agradecimentos}

Agradeço a minha orientadora Prof. Dra. Eloisa Dezen-Kempter, por dividir um pouco do seu vasto conhecimento na área que estamos atuando e a nossa instituição (Unicamp - Universidade Estadual de Campinas), mostrando novos caminhos para o conhecimento.

\footnotetext{
${ }^{1}$ CORY, C. Graphica Rio, s.1, 2011. BIM - THE IMPACT ON ENGINEERING \& GRAPHIC COMMUNICATION EDUCATION. In: IX INTERNATIONAL CONFERENCE ON GRAPHICS ENGINEERING FOR ARTS AND DESIGN.

2 A Sinduscon- Rio, Sindicato da Industria da Construção Civil no Estado do Rio de Janeiro. INTRODUÇÃO AO BIM: CONCEITOS GERAIS E PROCESSOS DE IMPLANTAÇÃO. s. d

3 National Institute of Building Sciences - NIBS (2007). National Building Information Modeling Standard. Version 1 - Part1: Overview, Principles, and Methodologies
} 